\title{
PANCREATICOPLEURAL FISTULA- A RARE CAUSE OF HAEMORRHAGIC PLEURAL EFFUSION
}

\author{
Aditi Baruah¹, Hemanta Kr. Dutta², Nibedita Paul33, Sutharson Ramasamy 4 \\ ${ }^{1}$ Associate Professor, Department of Paediatrics, Assam Medical College, Dibrugarh. \\ ${ }^{2}$ Associate Professor, Department of Paediatric Surgery, Assam Medical College, Dibrugarh. \\ ${ }^{3}$ Postgraduate Trainee, Department of Paediatrics, Assam Medical College, Dibrugarh. \\ ${ }^{4}$ Postgraduate Trainee, Department of Paediatrics, Assam Medical College, Dibrugarh.
}

HOW TO CITE THIS ARTICLE: Baruah A, Dutta HK, Paul N, et al. Pancreaticopleural fistula- a rare cause of haemorrhagic pleural effusion. J. Evolution Med. Dent. Sci. 2017;6(67):4823-4825, DOI: 10.14260/Jemds/2017/1046

\section{PRESENTATION OF CASE}

A 10-year-old boy presented with complaints of pain abdomen for 8 months, which had increased in severity for 15 days prior to admission along with fever, difficulty in respiration and right-sided dull aching chest pain. On examination, he was pale and tachypnoeic with a normal nutritional status. The trachea was shifted towards left, stony dullness was noted on percussion and breath sounds were decreased on the right side of the chest. Tenderness was present over epigastrium and right hypochondrium.

\section{CLINICAL DIAGNOSIS}

Clinically, the case was diagnosed as right-sided bacterial pleural effusion with chronic abdominal pain. Further investigations were planned to confirm the diagnosis and to find out the aetiology.

\section{DIFFERENTIAL DIAGNOSIS}

Differential diagnoses can be tubercular pleural effusion or haemorrhagic pleural effusion (rare). Differential diagnoses of pain abdomen can be hepatic abscess, right subphrenic abscess, pancreatic pseudocyst and acute or chronic pancreatitis. So immediate chest $\mathrm{x}$-ray and pleural tapping were planned.

\section{PATHOLOGICAL AND RADIOLOGICAL DISCUSSION}

Routine blood examination showed $\mathrm{Hb} 12.3 \mathrm{gm} \%$, TLC $18,800 / \mathrm{mm} 3$ with $87 \%$ neutrophils and ESR $30 \mathrm{~mm}$ AEFH. Chest X-ray showed total homogenous opacification of the right hemithorax with gross mediastinal shift towards the left. On aspiration, pleural fluid was found to be haemorrhagic. Pleural fluid analysis showed protein 3.8 $\mathrm{gm} / \mathrm{dL}$, sugar $40 \mathrm{mg} / \mathrm{dL}$, cell count 580 cells/cumm, mostly lymphocytes and presence of plenty of RBCs. There were no malignant cells. ADA was normal. Culture of pleural fluid showed growth of Acinetobacter baumannii. Tuberculin test was negative. PT, APTT, INR and platelet count were normal. Common causes of haemorrhagic pleural effusion are malignant effusion (most commonly Lymphoma), traumatic effusion, tubercular effusion or bleeding diathesis. The patient was started empirically on Vancomycin, which was changed to Imipenem later as per the sensitivity report.

Financial or Other, Competing Interest: None.

Submission 17-07-2017, Peer Review 10-08-2017,

Acceptance 16-08-2017, Published 21-08-2017.

Corresponding Author:

Dr. Aditi Baruah,

Associate Professor,

Department of Paediatrics,

Assam Medical College, Dibrugarh.

E-mail:dr_aditib@hotmail.com

DOI: $10.14260 /$ jemds $/ 2017 / 1046$

(c) $($ ) $(-$
Anti-tubercular therapy was not started, as Mantoux test and pleural fluid ADA were normal.

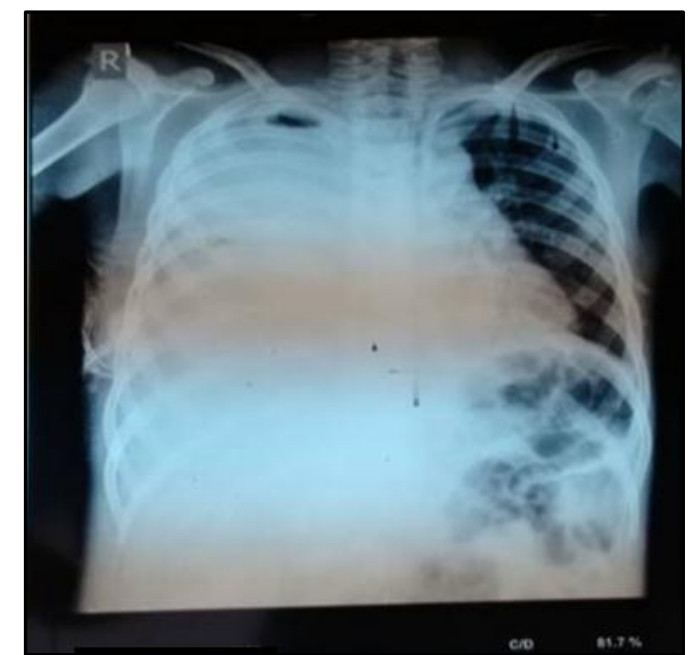

Figure 1. Chest X-ray showing Total Homogenous Opacification of the Right Hemithorax with Gross Mediastinal Shift towards the Left

HRCT thorax was done and it showed right-sided massive pleural effusion with collapse and consolidation of the underlying lung parenchyma. In spite of repeated aspirations, pleural fluid rapidly re-accumulated causing increasing distress to the patient. An intercostal chest tube was inserted with controlled drainage as the fluid was haemorrhagic. Pain and tenderness in the epigastrium, however, persisted. A CECT abdomen was done to evaluate the chronic abdominal pain and tenderness and it revealed features of acute pancreatitis with multi-loculated collection in the right hepatorenal pouch and massive right-sided pleural effusion. Acute pancreatitis with right-sided massive pleural effusion, which rapidly recollected following repeated drainage led us to suspect a fistulous connection. Amylase and lipase levels in serum and pleural fluid were sent and was found to be significantly raised. Pleural fluid amylase and lipase levels were disproportionately raised when compared with the corresponding serum values. The amylase and lipase levels in serum and pleural fluid were (235.6 U/L and 3123.7 U/L) and (145.7 U/L and $1596 \mathrm{U} / \mathrm{L}$ ) respectively. The differential diagnosis for amylase-rich pleural effusion includes acute pancreatitis, cancer of lung, pneumonia, oesophageal perforation, lymphoma, leukaemia, liver cirrhosis, hydronephrosis and pulmonary tuberculosis.[1] Subsequently, to find out the communication between the pleural cavity and pancreatic duct, an MRCP was done which showed features of acute on chronic pancreatitis and a long fistulous tract was noted from the Major Pancreatic Duct (MPD) from the head of pancreas, extending along the right sub-hepatic space and 
hepatorenal pouch into the right pleural cavity via a welldefined transdiaphragmatic tract.

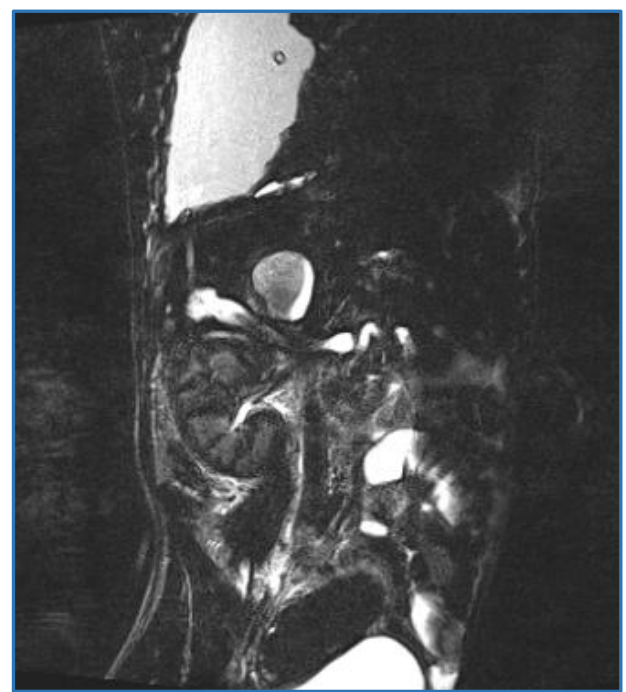

Figure 2. MRCP showing Dilated MPD with Atrophied Pancreatic Parenchyma and a Long Fistulous Tract from MPD from the Region of the Head of Pancreas and Extends along the Right Subhepatic Space and Hepatorenal Pouch into the Right Pleural Cavity via a well-defined Trans-

Diaphragmatic Tract in the Right Postero-Lateral aspect of Hemidiaphragm

\section{DISCUSSION OF MANAGEMENT}

After confirmation of the diagnosis of pancreatico-pleural fistula, the patient was started on total parenteral nutrition (TPN) and subcutaneous octreotide, following which the drainage from the chest tube decreased markedly along with marked symptomatic improvement. After 2 weeks of TPN, the patient was started on liquid and semisolid soft energy rich oral feeding. However, the patient developed pyopneumothorax on right side and needed thoracotomy and decortication. As the pleural fluid continued to drain from the chest tube, the patient was planned for surgery; 10 days after decortications a pylorus preserving pancreaticoduodenectomy was performed.

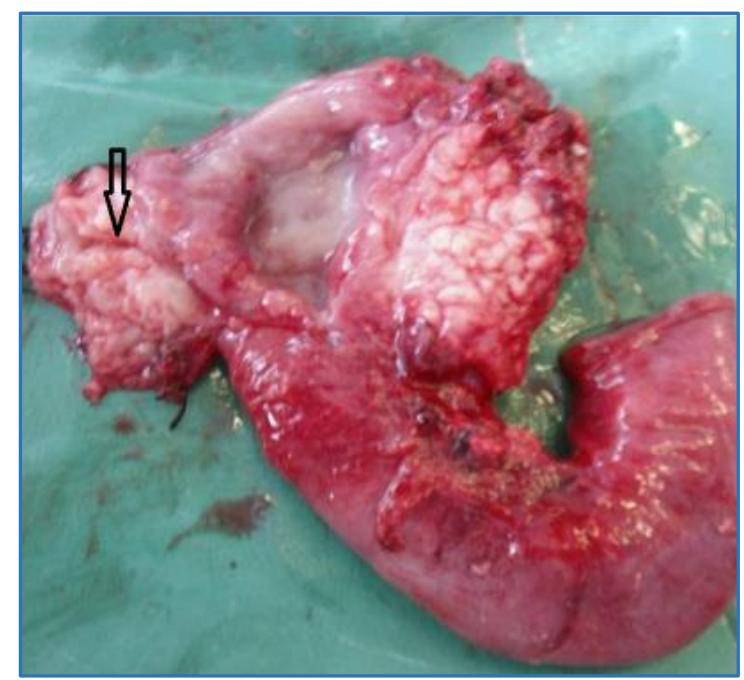

Figure 3. Resected Specimen of the Head of the Pancreas with Part of Duodenum. Arrow Mark showing Dilated MPD with Narrowing towards the Head of Pancreas
The patient had an uneventful recovery. The chest tube was removed and he was discharged post-operatively on Day 8. He was asymptomatic on 2 weeks and 1-month followup visit.

\section{FINAL DIAGNOSIS}

The final diagnosis of our case was Pancreatico-Pleural Fistula (PPF), which is a rare entity and accounts for less than $1 \%$ of cases of pleural effusion. ${ }^{1}$ Incidence varies between $0.4 \%-4.5 \% .^{2}$ It is rarer in the paediatric population. It occurs due to disruption of the main pancreatic duct, resulting in leakage of pancreatic fluid into the pleural space ${ }^{2-6}$ due to acute or chronic pancreatitis or may follow traumatic or surgical disruption of the pancreatic duct or rupture of a pseudo-pancreatic cyst. PPF is characterised by massive pleural effusion with high amylase content and has a tendency to recur following treatment. While conservative management with inhibition of pancreatic secretion with octreotide may achieve closure of fistula in $31 \%$ to $45 \%$ of cases, surgery leads to healing in $80 \%$ to $90 \%$ of cases. ${ }^{2-6}$

There are very few documented cases of pancreaticopleural fistula presenting as non-resolving unilateral pleural effusion. ${ }^{7}$ PPF presenting as right-sided pleural effusion with intradiaphragmatic fistula rather than fistula through the diaphragmatic hiatus $8,9,10$ is rarer still. The classical presentation is that of an alcoholic middle-aged man who presents with respiratory distress and then found to have left-sided pleural effusion. ${ }^{6}$ Biliary duct obstruction constitutes the major aetiological factor in children.8,11 Although rare, right-sided or bilateral pleural effusion is also seen in such cases. ${ }^{12}$

Very few cases of PPF have been reported in literature till now. ${ }^{12}$ In a study done by Ali $\mathrm{T}$ et al from University of Oklahoma Health Sciences Center, USA (2009), common presenting complaints of PPF were dyspnoea (65\%) followed by abdominal pain (29\%), cough (27\%) and chest pain (23\%). Similarly, a case report published by Wypych K et al (2011) where presenting feature was left-sided pleural effusion $^{12}$ and according to literature left-sided pleural effusion is the commonest presentation. In our case, the patient presented with haemorrhagic right-sided pleural effusion which is not common. 3,8

Evaluation for the common aetiologies was unfruitful in our case and diagnosis was made only following the HRCT thorax and CECT abdomen, which suggested a PPF and the presence of high amylase and lipase levels in pleural fluid clinched the diagnosis. MRCP is considered the method of choice for suspected PPF. ${ }^{13}$ The entire fistulous tract could be delineated in our case by MRCP. It was peculiar to note that the fistulous tract ran intra-diaphragmatically rather than through the diaphragmatic hiatus, which is a common occurrence.8,9,10 We noticed significant reduction of secretions with octreotide, which has been found to also shorten the time to fistula closure. ${ }^{14}$ ERCP and stent placement is a non-operative therapy for PPF, but with variable result. ${ }^{8}$ Surgical intervention is the definitive line of management for PPF. Pylorus preserving pancreaticoduodenectomy was performed in our case as pancreatic resection and enteropancreatic anastomosis constitute the methods of surgical intervention to achieve drainage of pancreatic secretions. ${ }^{4}$ 
So, PPF as a probable cause of haemorrhagic pleural effusion should be kept in mind particularly when associated with chronic abdominal pain. Because of the rarity of the condition usually the diagnosis is delayed, hence a high index of suspicion is required for early diagnosis and management.

\section{REFERENCES}

[1] Rockey DC, Cello JP. Pancreaticopleural fistula. Report of 7 patients and review of the literature. Medicine 1990;69(6):332-44.

[2] Burgess NA, Moore HE, Williams JO, et al. A review of pancreatico-pleural fistula in pancreatitis and its management. HPB Surgery 1992;5(2):79-86.

[3] Hastier P, Rouquier P, Buckley M, et al. Endoscopic treatment of wirsungo-cysto-pleural fistula. Eur J Gastroenterol Hepatol 1998;10(6):527-9.

[4] King JC, Reber HA, Shiraga S, et al. Pancreatic-pleural fistula is best managed by early operative intervention. Surgery 2010;147(1):154-9.

[5] Chebli JM, Gaburri PD, de Souza AF, et al. Internal pancreatic fistulas: proposal of a management algorithm based on case series analysis. J Clin Gastroenterol 2004;38(9):795-800.

[6] Oh YS, Edmundowicz SA, Jonnalagadda SS, et al. Pancreaticopleural fistula: report of two cases and review of literature. Dig Dis Sci 2006;51(1):1-6.
[7] Miller JA, Maldjian P, Seeff J. Pancreaticopleural fistula. An unusual cause of persistent unilateral pleural effusion. Clin Imaging 1998;22(2):105-7.

[8] Materne R, Vranckx P, Pauls C, et al. Pancreaticopleural fistula: diagnosis with magnetic resonance pancreatography. CHEST Journal 2000;117(3):912-4.

[9] Chan EE, Shelat VG. Pancreaticopleural fistula causing massive right hydrothorax and respiratory failure. Journal of the Pancreas 2005;6(2):152-61.

[10] Wronski M, Slodkowski M, Cebulski W, et al. Optimizing management of pancreaticopleural fistulas. World Journal of Gastroenterology 2011;17(42):4696703.

[11] Sonoda S, Taniguchi M, Sato T, et al. Bilateral pleural fluid caused by a pancreaticopleural fistula requiring surgical treatment. Intern Med 2012;51(18):2655-61.

[12] Wypych K, Serafin Z, Gałązka P, et al. Pancreaticopleural fistulas of different origin: report of two cases and a review of literature. Pol J radiol 2011;76(2):56-60.

[13] Ali T, Srinivasan N, Le V, et al. Pancreaticopleural fistula. Pancreas 2009;38(1):e26-31.

[14] Reechatipichitkul W, Bowornkitiwong T, Utchariyaprasit E. Chronic pancreatitis presenting with right pleural effusion: a case report. Med Assoc Thai 2010;93(3):378-82. 